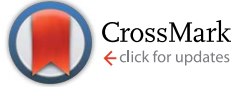

Cite this: RSC Adv., 2015, 5, 30500

\title{
Ozonolysis of a series of C7-C9 unsaturated biogenic aldehydes: reactivity study at atmospheric pressure $\uparrow$
}

\begin{abstract}
Elizabeth Gaona Colmán, ${ }^{a}$ María B. Blanco, ${ }^{* a}$ Ian Barnes ${ }^{b}$ and Mariano A. Teruel ${ }^{\star a}$
Rate coefficients for the reactions of $\mathrm{O}_{3}$ with trans-2-heptenal, trans-2-octenal and trans-2-nonenal have been determined at $298 \mathrm{~K}$ and $(990 \pm 10)$ mbar in an environmental chamber with in situ FTIR spectroscopy. The following rate coefficients in units of $k_{\mathrm{O}_{3}} \times 10^{18}\left(\mathrm{~cm}^{3}\right.$ molecule $\left.\mathrm{c}^{-1} \mathrm{~s}^{-1}\right)$ were obtained: $(2.47 \pm 0.73)$ for trans-2-heptenal, $(2.37 \pm 0.68)$ for trans-2-octenal and $(2.05 \pm 0.20)$ for trans-2-nonenal. It is shown that rate coefficients for the addition of $\mathrm{O}_{3}$ molecules and $\mathrm{OH}$ radicals to the double bond of alkenes and unsaturated and oxygenated volatile organic compounds (OVOCs) at $298 \mathrm{~K}$ are related to a good approximation by the expression: $\log k_{\mathrm{OH}}=0.16 \log k_{\mathrm{O}_{3}}-7.55$. Furthermore, a correlation between the reactivity of unsaturated VOCs toward $\mathrm{O}_{3}$ molecules and the energies of the Highest Occupied Molecular Orbit (HOMO) of the unsaturated VOCs is presented and potential atmospheric implications of

the results are discussed.
\end{abstract}

Received 30th December 2014

Accepted 9th March 2015

DOI: $10.1039 / c 4 r a 17283 c$

www.rsc.org/advances

\section{Introduction}

Volatile Organic Compounds (VOCs) emitted from vegetation, often referred to as biogenic volatile organic compounds (BVOCs), are considered to be the main source of reactive species in the troposphere. ${ }^{1-3}$ Aldehydes play an important role in atmospheric chemistry since they are recognized as important key precursors in the formation of tropospheric ozone and $\mathrm{OH}$ radicals. ${ }^{4-7}$ They are also potential prolific sources of secondary organic aerosols through their reactions with atmospheric oxidants and photolysis. ${ }^{8}$

Aldehydes are ubiquitous gaseous chemical constituents in the atmosphere and are emitted by a variety of sources. They arise, for example, from incomplete fossil fuel combustion, are emitted by vegetation and are produced during biomass burning. The photochemical oxidation of most VOCs in the atmosphere results in the formations of aldehydes to some degree. ${ }^{4-7}$

As mentioned above, in the troposphere aldehydes can be photolyzed $^{6,7,9}$ and will also be subject to reaction with the main atmospheric oxidants $\mathrm{OH}$ radicals, $\mathrm{NO}_{3}$ radicals and $\mathrm{O}_{3}$ molecules. In the marine boundary layer and coastal regions

${ }^{a}$ INFIQC (CONICET, Facultad de Ciencias Quimicas, Universidad Nacional de Córdoba) Dpto. de Fisicoquímica. Ciudad Universitaria, 5000 Córdoba, Argentina. E-mail: mteruel@fcq.unc.edu.ar; mblanco@fcq.unc.edu.ar; Fax: +54 351 4334188; Tel: +54 3515353866 ext. 53531

${ }^{b}$ Physikalische \& Theoretische Chemie/FBC, Bergische Universitaet Wuppertal, Wuppertal, Germany

$\dagger$ Electronic supplementary information (ESI) available. See DOI: $10.1039 / \mathrm{c} 4 \mathrm{ra} 17283 \mathrm{c}$ reactions with $\mathrm{Cl}$ atoms can also be important. The combination of the photodissociation of aldehydes and reaction with the atmospheric oxidants represents, in many cases, an important source of free radicals in the lower atmosphere which can significantly influence the atmospheric oxidation capacity.,10

A number of reviews on the gas-phase kinetics of the reactions of $\mathrm{OH}, \mathrm{NO}_{3}, \mathrm{O}_{3}$ and $\mathrm{Cl}$ with different unsaturated aldehydes are available in the literature. ${ }^{4-7}$ For long chain $\left(>\mathrm{C}_{4}\right)$ unsaturated aldehydes rate coefficients have been reported, by different groups using absolute and relative kinetic techniques, for the reaction of $\mathrm{OH}$ with $E$-2-pentenal, $E$-2-hexenal, $E$-2-heptenal, $E$-2-octenal and $E$-2-nonenal at room temperature and in some cases also as a function of temperature. ${ }^{6,7}$ In the case of $\mathrm{NO}_{3}$, rate coefficients have been reported at room temperature for the reaction of $\mathrm{NO}_{3}$ with five $\mathrm{C}_{5}-\mathrm{C}_{8}$ aldehydes, $E$-2-pentenal, $E$-2-hexenal, $E$-2-heptenal, $Z$-4-heptenal and $E$-2-octenal using different techniques. Again in some cases the reactions were also studied as a function of temperature. ${ }^{6,7}$ Rate coefficients for the reaction of $\mathrm{Cl}$ with $\mathrm{C}_{5}-\mathrm{C}_{7}$ 2-enals (E-2-pentenal, E-2-hexenal, $E$-2-heptenal) have been reported in a single study by Rodríguez et al. ${ }^{11}$ who performed the measurements at $298 \mathrm{~K}$ using a relative kinetic method.

With regard to the ozonolysis of $>\mathrm{C}_{4}$ unsaturated aldehydes, which is the subject of this study, Sato et al. ${ }^{12}$ have determined rate coefficients at $298 \mathrm{~K}$ for the reaction of $\mathrm{O}_{3}$ with three pentenals, E-2-pentenal, 3-methyl-2-butenal and E-2-methyl-2butenal, using the relative kinetic method. Grosjean et al. ${ }^{13}$ and Atkinson et al. ${ }^{14}$ have both measured the rate coefficient for the reaction of $\mathrm{O}_{3}$ with $E$-2-hexenal at room temperature using absolute and relative methods, respectively. 
Since unsaturated aldehydes are released to the atmosphere in substantial amounts from combustion and vegetation and there are not many studies on the ozonolysis of these compounds, the motivation of this work was to investigate the ozonolysis of some longer carbon chain unsaturated aldehydes. The organic compounds studied in this work trans-2-heptenal, trans-2-octenal, trans-2-nonenal are biogenic aldehydes emitted from different types of vegetation. ${ }^{15-17}$ As part of a systematic study on the kinetics of the atmospheric reactions of different unsaturated oxygenated VOCs, we report in this study rate coefficients for the reactions of $\mathrm{O}_{3}$ molecules with the aforementioned aldehydes at $298 \mathrm{~K}$ and atmospheric pressure of synthetic air in a large volume photoreactor using the relative kinetic method:

$$
\begin{gathered}
\mathrm{CH}_{3} \mathrm{CH}_{2} \mathrm{CH}_{2} \mathrm{CH}_{2} \mathrm{CH}=\mathrm{CHC}(\mathrm{O}) \mathrm{H}+\mathrm{O}_{3} \rightarrow \text { Products, } \\
\mathrm{CH}_{3} \mathrm{CH}_{2} \mathrm{CH}_{2} \mathrm{CH}_{2} \mathrm{CH}_{2} \mathrm{CH}=\mathrm{CHC}(\mathrm{O}) \mathrm{H}+\mathrm{O}_{3} \rightarrow \text { Products, (2) } \\
\mathrm{CH}_{3} \mathrm{CH}_{2} \mathrm{CH}_{2} \mathrm{CH}_{2} \mathrm{CH}_{2} \mathrm{CH}_{2} \mathrm{CH}=\mathrm{CHC}(\mathrm{O}) \mathrm{H}+\mathrm{O}_{3} \rightarrow \text { Products. }
\end{gathered}
$$

To the best of our knowledge rate coefficients of the above reactions have not been previously reported and this work, therefore, represents the first kinetic study of the reactions.

Additionally, the reactivity of the unsaturated aldehydes studied in this work together with other unsaturated VOCs toward $\mathrm{O}_{3}$ molecules has been correlated (i) with the reactivity of the same VOCs toward $\mathrm{OH}$ radicals and (ii) with the energies of the Highest Occupied Molecular Orbit (HOMO) of the unsaturated compounds. Tropospheric lifetimes for the studied aldehydes have been calculated and potential atmospheric implications assessed.

The kinetic data and correlations presented here help to improve our understanding of the atmospheric oxidation mechanisms of aldehydes. They also help in assessments of the potential contributions of the compounds to the oxidizing capacity of the tropospheric and photochemical smog and SOA formation.

\section{Experimental section}

All the experiments were performed in a $1080 \mathrm{~L}$ chamber at $(298 \pm 2) \mathrm{K}$ in $990 \pm 10$ mbar of synthetic air. The chamber is composed of a cylindrical quartz vessel (total length $6.2 \mathrm{~m}$ and an inner diameter of $0.47 \mathrm{~m}$ ) closed at both ends by aluminum end flanges. The metal flanges contain ports for the introduction of bath gases and reactants into the chamber. A magnetically coupled Teflon mixing fan is mounted inside the chamber to ensure homogeneous mixing of the reactants. The reactor can be evacuated by a pumping system consisting of a turbomolecular pump backed by a double stage rotary fore pump to $10^{-3}$ Torr. A White-type mirror system mounted internally in the chamber and coupled to a FTIR spectrometer Nicolet Nexus equipped with a liquid nitrogen cooled mercury-cadmiumtelluride (MCT) detector enables 'in situ' monitoring of the reactants in the infrared range $4000-700 \mathrm{~cm}$. The White mirror system was operated with the total optical absorption path length set to $484.7 \mathrm{~m}$ and infrared spectra were recorded with a spectral resolution of $1 \mathrm{~cm}^{-1}, 100$ interferograms were co-added per spectrum over a period of more than $1 \mathrm{~min}$ and 15 such spectra were recorded per experiment. The chamber is described in greater detail elsewhere. ${ }^{\mathbf{1 8 , 1 9}}$ Ozone was added stepwise to mixtures containing the unsaturated aldehydes and reference compound. An electrical discharge in a flow of pure oxygen was used to generate ozone. The initial concentrations of reactants in (ppmV) were approximately: 0.9 for trans-2-heptenal; 0.8 for trans-2-octenal; 0.7 for trans-2-nonenal; 3.0 for ethene; 4.0 for 1,3-butadiene; 0.5 for vinyl propionate and 6-9 for ozone. The reactants were monitored at the following infrared frequencies $\left(\mathrm{cm}^{-1}\right)$ : trans-2-heptenal at 3077-2657; trans-2-octenal at 3000-2650; trans-2-nonenal at 3011-2649; ethene at 949; 1,3-butadiene at 908 and vinyl propionate at 1170. Typical IR spectra of the kinetics experiments performed for the reactions of $\mathrm{O}_{3}$ with trans-2-heptenal, trans-2-octenal and trans-2-nonenal are presented in the ESI as Fig. S1-S3, $\dagger$ respectively. In addition, the concentration-time profiles for the three unsaturated aldehydes (trans-2-heptenal, trans-2-octenal and trans-2-nonenal) are presented as Fig. S4-S6, respectively in the ESI. $\dagger$

\section{Results and discussion}

Rate coefficients for the reactions of the aldehydes with $\mathrm{O}_{3}$ were determined using the relative rate method in which the rates of decay of the aldehydes were monitored relative to the decay of reference compounds.

$$
\begin{aligned}
& \mathrm{O}_{3}+\text { aldehyde } \rightarrow \text { products, } k_{1} \\
& \mathrm{O}_{3}+\text { reference } \rightarrow \text { products, } k_{2}
\end{aligned}
$$

If the unsaturated aldehydes and reference organics are removed solely by reaction with $\mathrm{O}_{3}$ molecules according to eqn (4) and (5) then (6) is valid:

$$
\ln \left\{\frac{[\text { aldehyde }]_{0}}{[\text { aldehyde }]_{t}}\right\}=\frac{k_{1}}{k_{2}} \ln \left\{\frac{[\text { reference }]_{0}}{[\text { reference }]_{t}}\right\}
$$

where $[\text { aldehyde }]_{0},[\text { reference }]_{0}$, [aldehyde $]_{t}$ and $[\text { reference }]_{t}$ are the concentrations of the unsaturated aldehyde compound under study and the reference compound at times $t=0$ and $t$, respectively, and $k_{1}$ and $k_{2}$ are the rate coefficients of reactions (4) and (5) respectively. Experiments were carried out to assess the loss of the unsaturated aldehyde and reference compound through deposition to the reactor wall. The wall losses of the unsaturated aldehyde and reference compound before the addition of $\mathrm{O}_{3}$ were found to be negligible. Three experiments were performed per reference compound and two reference compounds were employed for each of the investigated aldehydes. Data plotted in the form of eqn (6) are presented in Fig. 1-3 and the values of the rate coefficient $k_{1} / k_{2}$ are summarized in Table 1 together with the absolute values of the rate coefficients for the reactions of $\mathrm{O}_{3}$ with the aldehydes calculated from the $k_{1} / k_{2}$ ratios. The error bars in Fig. 1-3 are the 


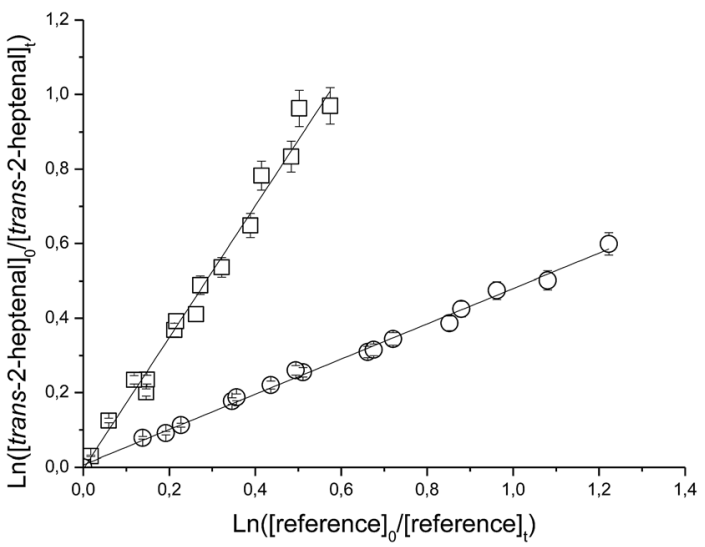

Fig. 1 Plot of the kinetic data for the reaction of $\mathrm{O}_{3}$ molecules with trans-2-heptenal measured relative to ethene $(\square)$ and vinyl propionate $(O)$ at $(298 \pm 2) \mathrm{K}$ and atmospheric pressure of air.

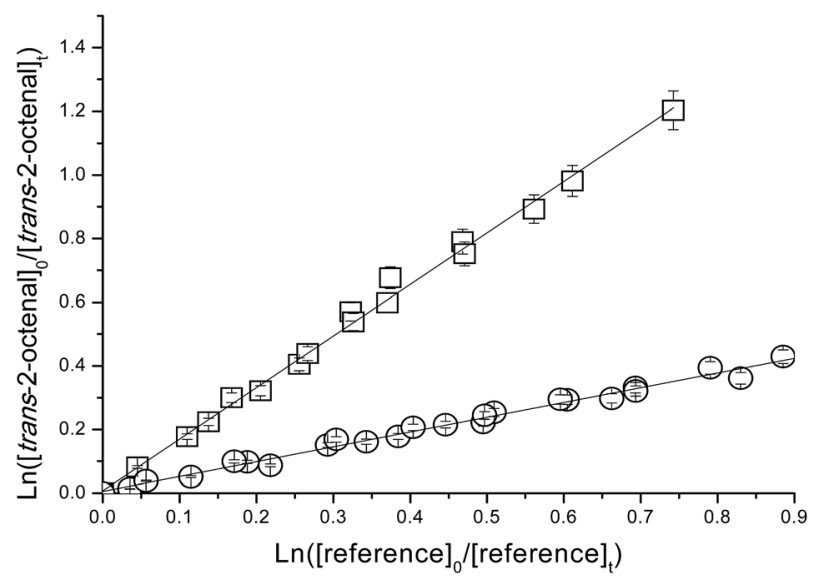

Fig. 2 Plot of the kinetic data for the reaction of $\mathrm{O}_{3}$ molecules with trans-2-octenal measured relative to ethene ( $\square$ ) and vinyl propionate $(\mathrm{O})$ at $(298 \pm 2) \mathrm{K}$ and atmospheric pressure of air.

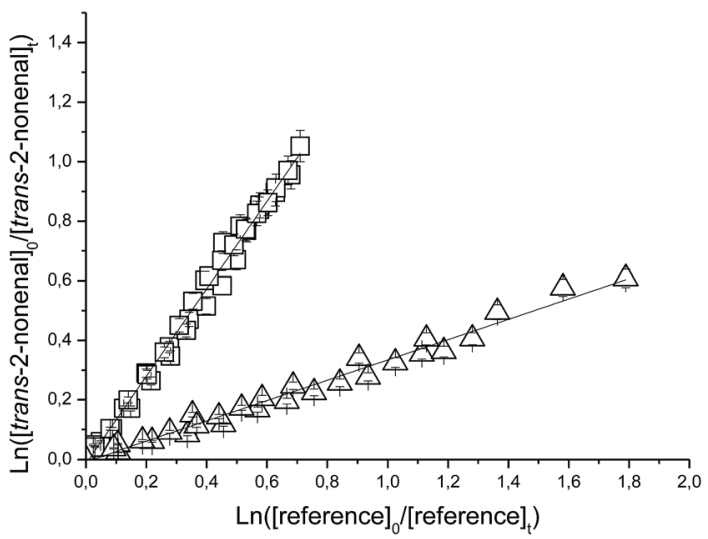

Fig. 3 Plot of the kinetic data for the reaction of $\mathrm{O}_{3}$ molecules with trans-2-nonenal measured relative to ethene $(\square)$ and 1,3-butadiene $(\Delta)$ at $(298 \pm 2) \mathrm{K}$ and atmospheric pressure of air.
$2 \sigma$ statistical errors from the scatter in the plots. The rate coefficients for the reactions of $\mathrm{O}_{3}$ molecules with the unsaturated aldehydes were placed on an absolute basis using the following values for the reference reactions at $298 \mathrm{~K}: \mathrm{O}_{3}+$ ethene $(1.37 \pm 0.08) \times 10^{-18} \mathrm{~cm}^{3}$ molecule ${ }^{-1} \mathrm{~s}^{-1} ;^{20} \mathrm{O}_{3}+1,3$-butadiene (6.3 $\pm 0.4) \times 10^{-18} \mathrm{~cm}^{3}$ molecule ${ }^{-1} \mathrm{~s}^{-1}$ (ref. 20) and $\mathrm{O}_{3}+$ vinyl propionate $(5.3 \pm 1.3) \times 10^{-18} \mathrm{~cm}^{3}$ molecule ${ }^{-1} \mathrm{~s}^{-1}{ }^{21}$

The errors quoted for the rate coefficients for the reactions of $\mathrm{O}_{3}$ with the aldehydes in Table 1 are a combination of the $2 \sigma$ statistical errors from the linear regression analyses of the plots plus the corresponding error of the reference reaction rate coefficient. As can be seen from Table 1 there is good agreement between the rate coefficients obtained for the reaction of $\mathrm{O}_{3}$ with the aldehydes using two different reference compounds. Because of this good agreement, we prefer to give final rate coefficients for the reactions which are an average of all the determinations, i.e.

$$
\begin{aligned}
& k_{\left(\mathrm{O}_{3}+\text { trans-2-heptenal }\right)}=(2.47 \pm 0.73) \times 10^{-18} \mathrm{~cm}^{3} \text { molecule }{ }^{-1} \mathrm{~s}^{-1} \\
& k_{\left(\mathrm{O}_{3}+\text { trans-2-octenal }\right)}=(2.37 \pm 0.68) \times 10^{-18} \mathrm{~cm}^{3} \text { molecule }{ }^{-1} \mathrm{~s}^{-1} \\
& k_{\left(\mathrm{O}_{3}+\text { trans-2-nonenal }\right)}=(2.05 \pm 0.20) \times 10^{-18} \mathrm{~cm}^{3} \text { molecule }{ }^{-1} \mathrm{~s}^{-1}
\end{aligned}
$$

It is well established that the ozonolysis of alkenes produces $\mathrm{OH}$ radicals which can interfere with relative kinetic studies of the type presented here. To minimize this inference an organic compound or $\mathrm{CO}$ is often added to the system to scavenge the $\mathrm{OH}$ radicals. The rate coefficients for the reactions of the unsaturated aldehydes under investigation in this study are very high, thus in order to effectively scavenge any $\mathrm{OH}$ radicals produced during the ozonolysis reaction high concentrations of a scavenger would be necessary. Since such high concentrations of the scavenger in the reaction system would render monitoring of the reactants in the infrared impossible, the experiments have been performed in the absence of a scavenger. We have obtained values of the rate coefficients for the reactions of $\mathrm{O}_{3}$ with the aldehydes using two reference compounds which are in excellent agreement with one another. Since the rate coefficients for the reactions of $\mathrm{O}_{3}$ with the reference compounds differ by a factor of approximately 4 and their rate coefficients with $\mathrm{OH}$ are all quite different we argue that any influence by $\mathrm{OH}$ in the reaction systems can not be very significant.

Since all of the hydrocarbons in the system will react with $\mathrm{OH}$ it would appear that in the systems investigated any interference by $\mathrm{OH}$, that might possibly be occurring, is largely selfcompensating. However, it is still important to keep in mind when making rate coefficient comparisons that the present values were determined in the absence of an $\mathrm{OH}$ radical scavenger.

The rate coefficients values obtained for the three reactions studied are very similar and within the error limits can be considered the same. The rate coefficients for the reactions of ozone with the three aldehydes have been estimated using the US EPA AOPWIN program which is based upon the structure- 
Table 1 Rate coefficient ratios $k_{1} / k_{2}$ and rate coefficients for the reactions of ozone with trans-2-heptenal, trans-2-octenal and trans-2-nonenal at $(298 \pm 2) \mathrm{K}$ in $(990 \pm 10) \mathrm{mbar}$ of air

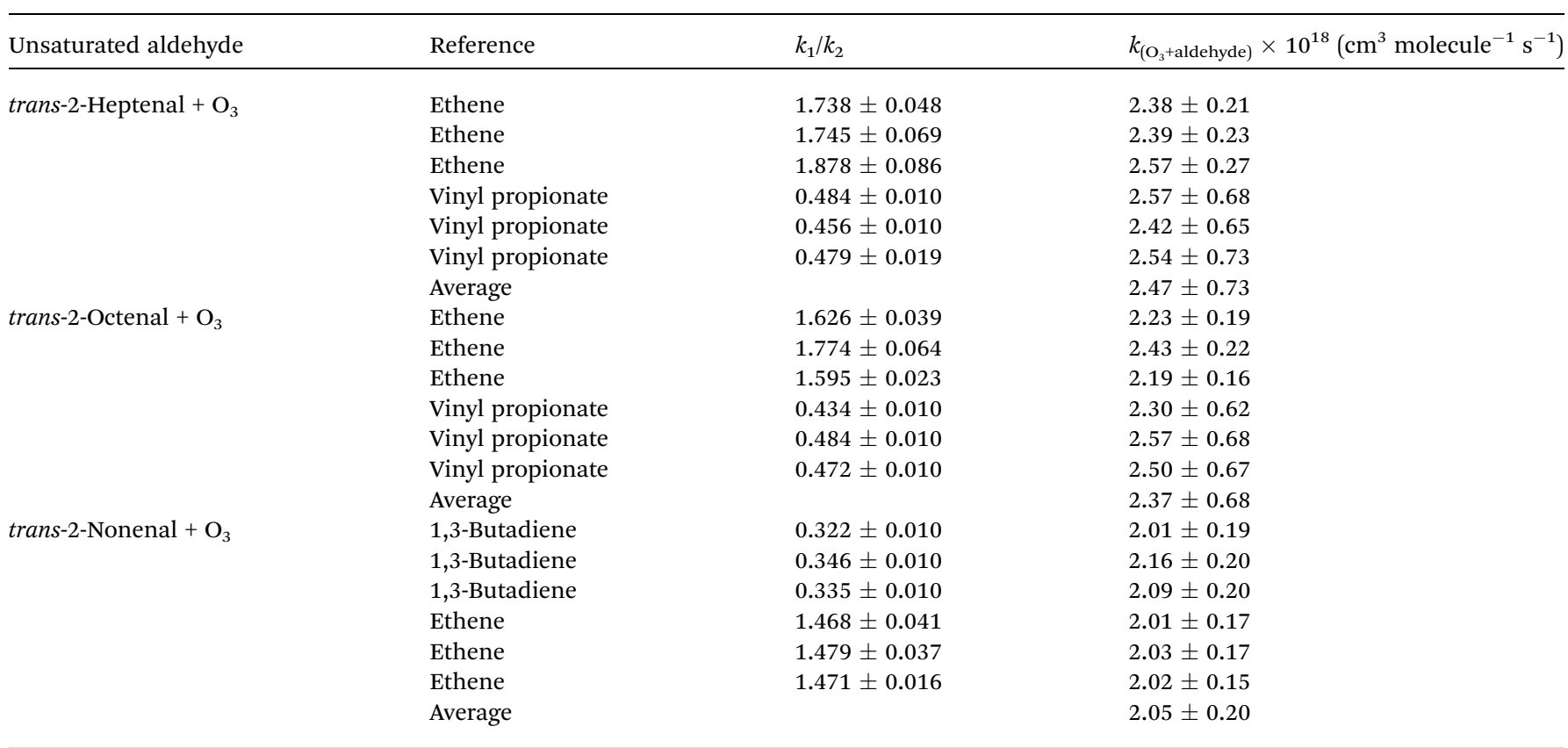

activity relationship (SAR) method described in Kwok and Atkinson. ${ }^{22}$ This estimation method predicts a rate coefficient value of $1.82 \times 10^{-18} \mathrm{~cm}^{3}$ molecule ${ }^{-1} \mathrm{~s}^{-1}$ for all three of the unsaturated aldehydes which is lower than experimental values reported here by approximately $35 \%$ for trans-2-heptenal, $30 \%$ for trans-2-octenal and 13\% for trans-2-nonenal. This agreement is quite acceptable considering the uncertainties in the rate coefficient determinations.

The rate coefficient of $(2.0 \pm 1.0) \times 10^{-18} \mathrm{~cm}^{3}$ molecule ${ }^{-1} \mathrm{~s}^{-1}$ reported by Atkinson et al. ${ }^{14}$ for the reaction of $\mathrm{O}_{3}$ with trans-2hexenal is very similar, within the error limits, to the rate coefficients determined in this work for the reactions of $\mathrm{O}_{3}$ with trans-2-heptenal, trans-2-octenal and trans-2-nonenal. This similarity in the reactivity for $\geq \mathrm{C} 6$ unsaturated-2-enals toward $\mathrm{O}_{3}$ supports that above $\mathrm{C} 6$ further increases in the alkyl chain length of the aldehyde has a negligible effect on the magnitude of the electron donation to the double bond.

Rate coefficients for the addition of $\mathrm{OH}$ and $\mathrm{NO}_{3}$ radicals, $\mathrm{Cl}$ atoms and $\mathrm{O}_{3}$ molecules to alkenes and unsaturated VOCs have been shown previously to correlate with the energy of the HOMO of the different VOCs. ${ }^{23-26}$ The electron density in the $\pi$ bond that is attacked by the $\mathrm{O}_{3}$ molecule should be reflected in the energy of the highest occupied molecular orbital ( $\left.E_{\text {номо }}\right)$ with the lowest negative value being expected for the compound with the largest rate coefficient. To contribute to extend the correlations reported previously for the rate coefficients of $\mathrm{OH}$ and $\mathrm{Cl}$ reactions with $E_{\text {Hомо }}$ energies, ${ }^{27}$ a new correlation for the ozonolysis of different unsaturated VOCs has been determined using the Gaussian 03 package. ${ }^{28}$ The geometry optimizations and initial values of the energies were obtained at the B3LYP level with a 6-311G(d,p) bases set. The $E_{\text {Hомо }}$ calculated for the unsaturated aldehydes and the other unsaturated VOCs are listed in Table 2. Fig. 4 shows a plot of the natural logarithms of the $\mathrm{O}_{3}$ rate coefficients plotted as a function of the calculated $E_{\text {Hомо }}$ in eV. A linear relationship is obtained. The linear relationship in Fig. 4 is well described by:

$$
\begin{aligned}
& -\ln k_{\mathrm{O}_{3}}\left(\mathrm{~cm}^{3} \text { molecule }{ }^{-1} \mathrm{~s}^{-1}\right)= \\
& \quad(9.52 \pm 1.12)\left(-E_{\mathrm{HOMO}}\right)+(26.50 \pm 2.35), r^{2}=0.97
\end{aligned}
$$

The quality of the correlation is such that it can be used for reasonable estimations of rate coefficients for the reactions of $\mathrm{O}_{3}$ molecules with other unsaturated VOCs where data does not yet exist.

In addition, we present for the first time, a correlation between $k_{\mathrm{OH}}$ and $k_{\mathrm{O}_{3}}$ for a wide range of different unsaturated VOCs. The rate coefficients for the reactions of different unsaturated VOCs with $\mathrm{O}_{3}$ molecules and $\mathrm{OH}$ radicals at $298 \mathrm{~K}$ are listed in Table 2 . The correlation obtained between the rate coefficients for the reactions of $\mathrm{O}_{3}$ molecules with a given alkene or unsaturated VOC and those for the corresponding reactions with $\mathrm{OH}$ radicals is shown in Fig. 5. A reasonable correlation is obtained and a least-squares treatment of the data points in Fig. 5 yields the following expression (with the rate coefficients in units of $\mathrm{cm}^{3}$ molecule ${ }^{-1} \mathrm{~s}^{-1}$ ):

$$
\log k_{\mathrm{OH}}=0.16 \log k_{\mathrm{O}_{3}}-7.55, r^{2}=0.95
$$

The quality of this correlation is also such that it can be used to make reasonable estimations of rate coefficients for reactions of $\mathrm{O}_{3}$ molecules with other unsaturated VOCs where data does not yet exist. 
Table 2 Rate coefficients of $\mathrm{O}_{3}$ and $\mathrm{OH}$ with different VOCs and $E_{\mathrm{HOMO}}$ for the corresponding VOCs

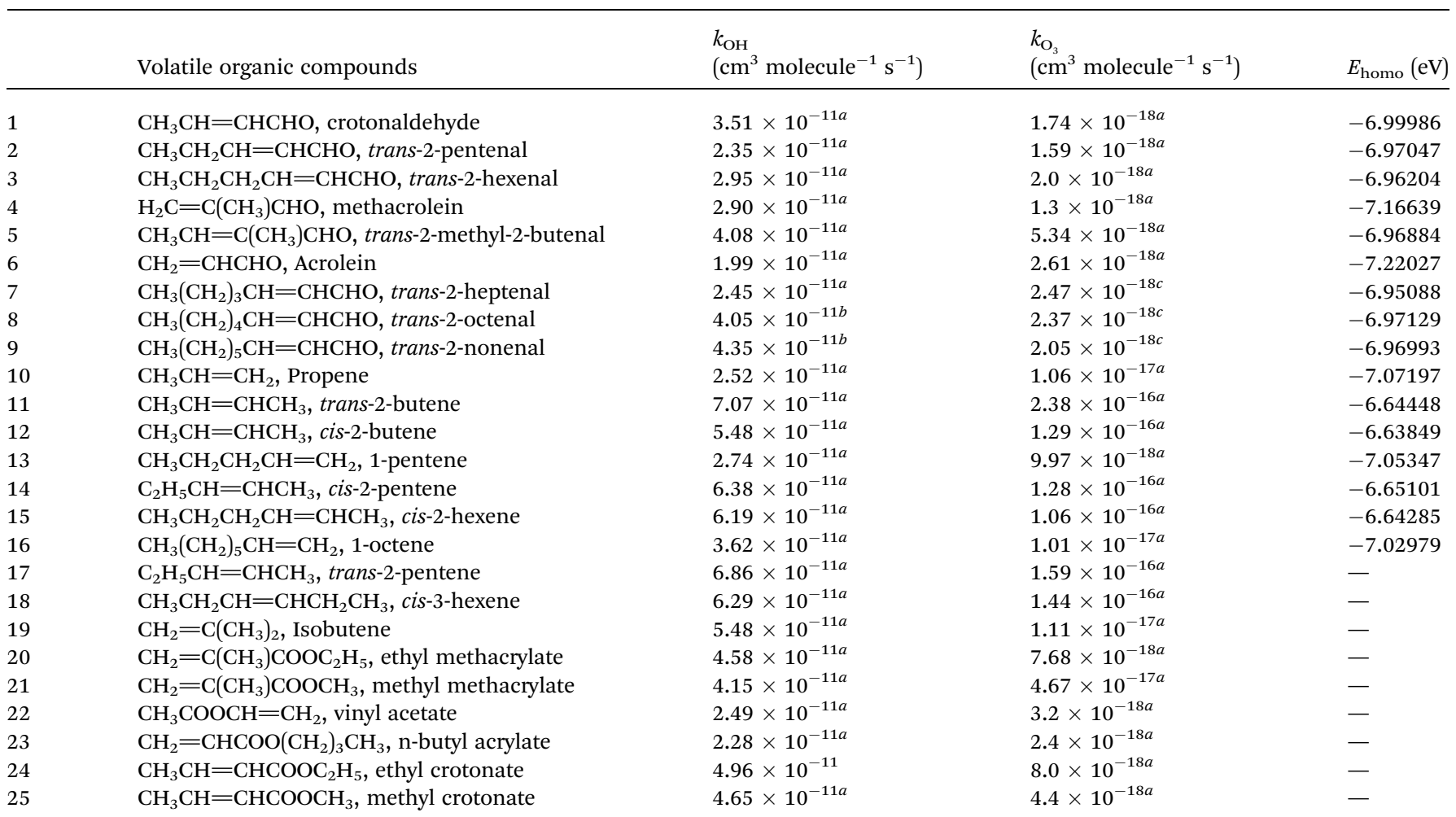

${ }^{a}$ Ref. 33. ${ }^{b}$ Ref.34. ${ }^{c}$ This work.

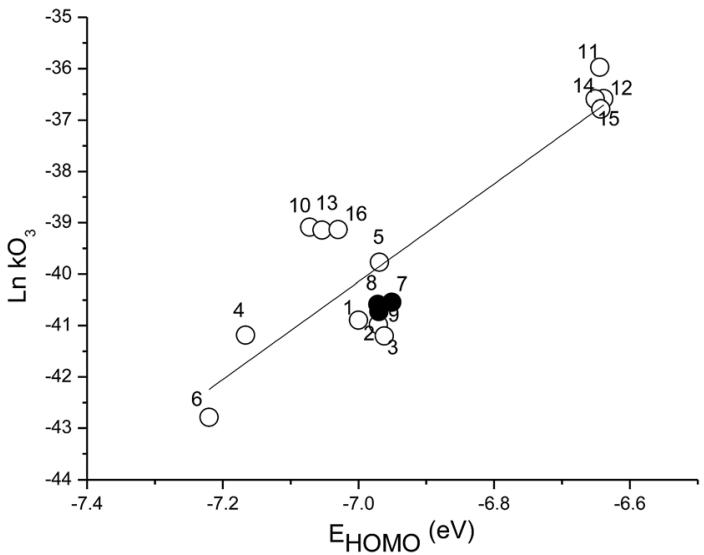

Fig. 4 Correlation of $\ln k_{\mathrm{O}_{3}}\left(\mathrm{~cm}^{3}\right.$ molecule $\left.{ }^{-1} \mathrm{~s}^{-1}\right)$ against $E_{\mathrm{HOMO}}$ calculated using the Gaussian 3.0 package B3LYP/6-311G(d,p) for the reactions of volatile organic compounds with ozone. The numbers correspond to the compounds listed in Table 2 and the filled circles highlight the aldehydes, trans-2-heptenal, trans-2-octenal and trans2-nonenal, studied in this work.

The atmospheric lifetime of the studied aldehydes with respect to reaction with the main tropospheric oxidants can be estimated using the expression:

$$
\tau_{x}=\frac{1}{k_{x} \times[\mathrm{X}]}
$$

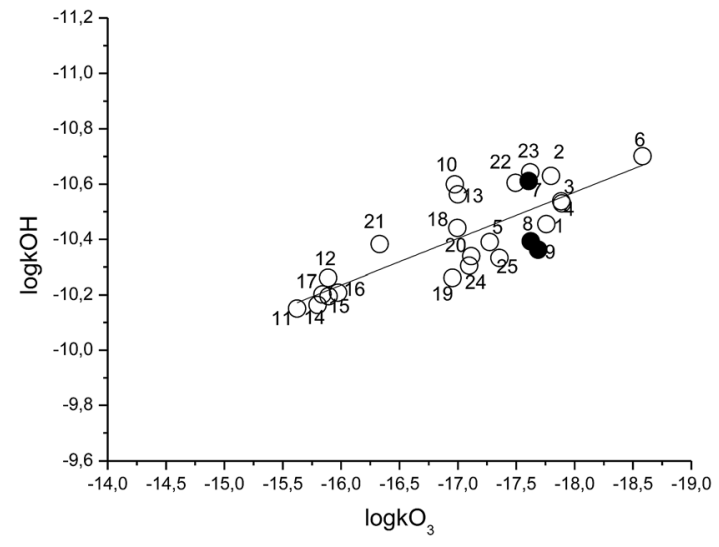

Fig. 5 Linear free energy plot of $\log \mathrm{kOH}_{\mathrm{OH}}$ against $\log \mathrm{k}_{\mathrm{O}_{3}}$ at room temperature for a series of unsaturated volatile organic compounds. The numbers correspond to the compounds listed in Table 2 and the filled circles highlight the aldehydes, trans-2-heptenal, trans-2-octenal and trans-2-nonenal, studied in this work.

where $\mathrm{X}=\mathrm{O}_{3}, \mathrm{OH}, \mathrm{NO}_{3}$ or $\mathrm{Cl}$ and $k_{x}$ is the rate coefficient of the aldehyde with the oxidant $\mathrm{X}$, The following typical tropospheric oxidant concentrations have been used in calculating the lifetimes: $\left[\mathrm{O}_{3}\right]=7 \times 10^{11}$ molecule $\mathrm{cm}^{-3} ;{ }^{29}[\mathrm{OH}]=2 \times 10^{6}$ radical $\mathrm{cm}^{-3} ; ;^{30}[\mathrm{Cl}]=1 \times 10^{4}$ atom $\mathrm{cm}^{-331}$ and $\left[\mathrm{NO}_{3}\right]=5 \times 10^{8}$ radical $\mathrm{cm}^{-3} .32$ The atmospheric lifetimes for the reaction of the aldehydes with ozone and the other oxidants, where data are available, are presented in Table 3. The lifetimes show that the 
Table 3 Estimated tropospheric lifetimes for the unsaturated aldehydes studied with respect to their reactions with $\mathrm{O}_{3}, \mathrm{OH}_{1} \mathrm{NO} \mathrm{O}_{3}$ and $\mathrm{Cl}$

\begin{tabular}{|c|c|c|c|c|c|c|c|c|}
\hline Aldehyde & $\begin{array}{l}k_{\mathrm{O}_{3}} \mathrm{~cm}^{3} \\
\text { molecule }^{-1} \mathrm{~s}^{-1}\end{array}$ & $\begin{array}{l}\tau_{\mathrm{O}_{3}} \\
\text { (days) }\end{array}$ & $\begin{array}{l}k_{\mathrm{OH}} \mathrm{cm}^{3} \\
\text { molecule }^{-1} \mathrm{~s}^{-1}\end{array}$ & $\begin{array}{l}\tau_{\mathrm{OH}} \\
\text { (hours) }\end{array}$ & $\begin{array}{l}k_{\mathrm{NO}_{3}} \mathrm{~cm}^{3} \\
\text { molecule } \\
-1 \mathrm{~s}^{-1}\end{array}$ & $\begin{array}{l}\tau_{\mathrm{NO}_{3}} \\
\text { (hours) }\end{array}$ & $\begin{array}{l}k_{\mathrm{Cl}} \mathrm{cm}^{3} \\
\text { molecule }^{-1} \mathrm{~s}^{-1}\end{array}$ & $\begin{array}{l}\tau_{\mathrm{Cl}} \\
\text { (days) }\end{array}$ \\
\hline trans-2-Heptenal & $2.47 \times 10^{-18 a}$ & 7 & $2.45 \times 10^{-11 b}$ & 6 & $\begin{array}{l}0.23 \times 10^{-13 d} \\
5.3 \times 10^{-15 e}\end{array}$ & $\begin{array}{l}0.4 \\
2\end{array}$ & $2.40 \times 10^{-10 f}$ & 5 \\
\hline trans-2-Octenal & $2.37 \times 10^{-18 a}$ & 7 & $40.5 \times 10^{-12 c}$ & 3 & $5.6 \times 10^{-15 e}$ & 2 & - & - \\
\hline trans-2-Nonenal & $2.05 \times 10^{-18 a}$ & 8 & $43.5 \times 10^{-12 c}$ & 3 & - & - & - & - \\
\hline
\end{tabular}

unsaturated aldehydes will be degraded by reaction with $\mathrm{NO}_{3}$ radical during the night and with $\mathrm{OH}$ radicals during the day. At the levels of $\mathrm{O}_{3}$ typically present in the troposphere, decay of the unsaturated aldehyde with $\mathrm{O}_{3}$ will be insignificant but could potentially be of some importance during episodes of elevated $\mathrm{O}_{3}$ levels. Wet and dry deposition will be a minor loss process for the aldehydes since they are highly volatile and sparingly soluble in water.

Degradation of longer chain aldehydes constitutes a significant source of aldehydes containing less carbon atoms than the precursor. In the presence of $\mathrm{OH}, \mathrm{NO}_{3}, \mathrm{O}_{3}$ longer chain unsaturated aldehyde will probably be degraded to much shorter chain aldehydes, which have longer lifetimes and can contribute effectively to tropospheric ozone and SOA formation. In addition, longer chain aldehydes in the course of their degradation can undergo isomerization reactions forming carbonyl compounds which in further oxidation reactions can form thermally stable PAN type compounds.

For the reactions studied in this work we expect, based on existing ozonolysis studies, that pentanal, hexanal and heptanal will be major reaction products from the reactions of $\mathrm{O}_{3}$ with trans-2-heptenal, trans-2-octenal and trans-2-nonenal, respectively. Glyoxal will also be a major reaction product for all three aldehydes. However, the exact nature and yields of the products formed in the ozonolysis of the unsaturated aldehydes studied here still remains to be elucidated.

\section{Acknowledgements}

The authors wish to acknowledge MINCYT (Argentina)-PICT 2012-1740, CONICET(PIP)- GI 2010-2012-cod: 11220090100623 (Argentina), SECyT-UNC-14306/24. (Córdoba, Argentina) and the EU project EUROCHAMP-2 EU. E2-2013-02-27-0086 for financial support of this research. E.G.C. wishes to acknowledge to CONICET for a doctoral fellowship and support.

\section{References}

1 A. Guenther, C. N. Hewitt, D. Erickson, R. Fall, C. Geron, T. Graedel, P. Harley, L. Klinger, M. Lerdau, W. A. Mckay, T. Pierce, B. Scholes, R. Steinbrecher, R. Tallamraju, J.Taylor and P. Zimmerman, J. Geophys. Res.: Atmos., 1995, 100(D5), 8873-8892, DOI: 10.1029/94JD02950.

2 J. Kesselmeier and M. Staudt, J. Atmos. Chem., 1999, 33(1), 23-88, DOI: 10.1023/a:1006127516791.
3 J. E. Williams, P. F. J. Van Velthoven and C. A. M. Brenninkmeijer, Atmos. Chem. Phys., 2013, 13, 2857-2891, DOI: 10.5194/acp-13-2857-2013.

4 P. Carlier, H. Hannachi and G. Mouvier, Atmos. Environ., 1986, 20, 2079-2099, DOI: 10.1016/0004-6981(86)90304-5.

5 A. Mellouki, G. Le Bras and H. Sidebottom, Chem. Rev., 2003, 103(12), 5077-5096, DOI: 10.1021/cr020526x.

6 J. G. Calvert, A. Mellouki, J. J. Orlando, M. J. Pilling and T. J. Wallington, The Mechanisms of Atmospheric Oxidation of the Oxygenates, Oxford University Press, New York, 2011.

7 E. Jiménez and I. Barnes, Environment, Energy and Climate Change I: Environmental Chemistry of Pollutants and Wastes, in The Handbook of Environmental Chemistry, vol. 32, 2015.

8 A. W. H. Chan, M. N. Chan, J. D. Surratt, P. S. Chhabra, C. L. Loza, J. D. Crounse, L. D. Yee, R. C. Flagan, P. O. Wennberg and J. H. Seinfeld, Atmos. Chem. Phys., 2010, 10, 7169-7188.

9 E. K. C. Lee and R. S. Lewis in Advances in photochemistry, ed. J. N. Pitts Jr, G. S. Hammond and K. Gollnick, vol. 12, Wiley, New York, 1980, pp. 1-96.

10 B. Finlayson- Pitts and J. Pitts Jr, Chemistry of the Upper and Lower Atmosphere-Theory, Experiments and Applications, ACADEMIC Press, 2000.

11 D. Rodríguez, A. Rodríguez, A. Notario, A. Aranda, Y. Díaz-deMera and E. Martínez, Atmos. Chem. Phys., 2005, 5, 34333440, DOI: 10.5194/acp-5-3433-2005.

12 K. Sato, B. Klotz, T. Taketsugu and T. Takayanagi, Phys. Chem. Chem. Phys., 2004, 6(15), 3969-3976, DOI: 10.1039/ B402496F.

13 E. Grosjean, D. Grosjean and J. H. Seinfeld, Int. J. Chem. Kinet., 1996, 28, 373-382.

14 R. Atkinson, J. Arey, S. M. Aschamann, S. B. Corchnoy and Y. Shu, Int. J. Chem. Kinet., 1995, 27, 941-955, DOI: 10.1002/kin.550271002.

15 K. Anjou and E. Von Sydow, Acta chemical scandinavica, 1967, 21, 945-952.

16 T. R. Kemp, Phytochemistry, 1975, 14, 2637-2638, DOI: 10.1016/0031-9422(75)85240-x.

17 Y. Xu and S. Barringer, J. Food Sci., 2010, 75, 268-273, DOI: 10.1111/j.1750-3841.2010.01537.x.

18 I. Barnes, K. H. Becker and T. Zhou, J. Atmos. Chem., 1993, 17, 353-373.

19 I. Barnes, K. H. Becker and N. Mihalopoulos, J. Atmos. Chem., 1994, 18, 267-289. 
20 J. Treacy, M. E. Hag, D. O'Farrell and H. Sidebottom, Ber. Bunsenges. Phys. Chem., 1992, 96(3), 422-427.

21 W. M. Meylan and P. H. Howard, Chemosphere, 1993, 26, 2293-2299.

22 E. C. Kwok and R. Atkinson, Atmos. Environ., 1995, 29, 16851695.

23 E. Gaona Colmán, M. B. Blanco, I. Barnes and M. Teruel, Chem. Phys. Lett., 2013, 579, 11-15, DOI: 10.1016/ j.cplett.2013.05.049.

24 C. Canosa-Mas, M. L. Flugge, M. King and R. Wayne, Phys. Chem. Chem. Phys., 2005, 7, 643-650, DOI: 10.1039/ B416574H.

25 M. D. King, C. E. Canosa-Mas and R. P. Wayne, Phys. Chem. Chem. Phys., 1999, 1, 2231-2238, DOI: 10.1039/a901193e.

26 C. Pfrang, M. D. King, C. E. Canosa-Mas, M. Flugge and R. P. Wayne, Atmos. Environ., 2007, 41(8), 1792-1802, DOI: 10.1016/j.atmosenv.2006.11.026.

27 M. B. Blanco, I. Bejan, I. Barnes, P. Wiesen and M. A. Teruel, Atmos. Environ., 2009, 43(38), 5996-6002, DOI: 10.1016/ j.atmosenv.2009.08.032.

28 M. J. Frisch, G. W. Schlegel, G. E. Scuseria, M. A. Robb, J. R. J. Cheeseman, A. Montgomery Jr, T. Vreven, K. N. Kudin, J. C. Burant and J. M. Millam, et al.Gaussian 03 Revision-D.01 Gaussian 03 Revision-D.01, Gaussian, Inc., Pittsburgh PA, 2003.
29 J. A. Logan, J. Geophys. Res.: Atmos., 1985, 90, 10463-10482, DOI: $10.1029 / J D 090 i D 06 p 10463$.

30 R. Hein, P. J. Crutzen and M. Heimann, Global Biogeochem. Cycles, 1997, 11, 43.

31 O. W. Wingenter, M. K. Kubo, N. J. Blake, T. W. Smith, D. R. Blake and F. S. Rowland, J. Geophys. Res., 1996, 101, 4331-4340.

32 Y. Shu and R. Atkinson, J. Geophys. Res.: Atmos., 1995, 100(D4), 7275-7281, DOI: 10.1029/95JD00368.

33 NIST-Chemical Kinetics Database on the Web - Standard Reference Database17, Version 7.0 (Web Version), Release 1.6.3, Data Version, 2011.

34 T. Gao, J. M. Andino, C. C. Rivera and M. Francisco Márquez, Int. J. Chem. Kinet., 2009, 41, 483-489, DOI: 10.1002/ kin. 20424.

35 J. Albaladejo, B. Ballesteros, E. Jimenez, P. Martin and E. Martinez, Atmos. Environ., 2002, 36, 3231-3239, DOI: 10.1016/S1352-2310(02)00323-0.

36 Z. Zhao, S. Husainy and G. D. Smith, J. Phys. Chem. A, 2011, 115(44), 12161-12172, DOI: 10.1021/jp206899w.

37 J. Kerdouci, B. Picquet-Varrault, R. Durand-Jolibois, C. Gaimoz and J. F. J. Doussin, J. Phys. Chem. A, 2012, 116(41), 0135-10142, DOI: 10.1021/jp3071234. 